\title{
Pesca artesanal en la costa de Jalisco. Conflictos en torno a la conservación biocultural
}

\section{Paulina Martínez González Antonio Corgos López-Prado}

\begin{abstract}
La pesca artesanal en la costa del estado de Jalisco, México, es de gran importancia económica para las comunidades que habitan en el litoral. Es una actividad compatible con la conservación biocultural. Sin embargo, está amenazada por las dinámicas de apropiación de territorios y recursos naturales bajo los criterios de la racionalidad económica. Estas dinámicas se ilustran en el caso del conflicto socioambiental en Careyitos.
\end{abstract}

$\mathrm{L}$ a costa de Jalisco se distingue por albergar una alta biodiversidad. Tiene una longitud de 352 kilómetros y una superficie de 1'451,466 hectáreas, que corresponden a $17.5 \%$ del territorio de la entidad. El gobierno del estado informa que existen cuando menos 18 tipos de ecosistemas en la costa, clasificados como selvas media y baja caducifolias, selva espinosa, bosque de pinos y encinos, manglares, vegetación de dunas y arrecifes coralinos. ${ }^{1}$ Con respecto a la flora y fauna, se han registrado 1400 especies de plantas vasculares y 689 de vertebrados: 26 especies de anfibios, 84 de reptiles, 151 de mamíferos y
428 de aves. Asimismo, el 30\% de los endemismos del país se encuentran en la zona: 19 especies de peces y $36 \%$ de las especies de tortugas marinas conocidas. ${ }^{2}$ Por estas razones, las autoridades gubernamentales han delimitado algunas áreas destinadas a la conservación, entre las que se distinguen, por su importancia, la Reserva de la Biósfera Chamela-Cuixmala y los Santuarios de Protección a la Tortuga Marina en las playas de Mismaloya, Cuixmala, Tecuán y Teopa. ${ }^{3}$

Con respecto a la población, la mayor parte se concentra en los centros urbanos que proporcionan servicios turísticos, particularmente en Puerto Vallarta

Paulina Martínez González es candidata a doctora en Ciencias Sociales por la Universidad de Guadalajara. Coordina la Licenciatura en Sociología en el Centro Universitario de la Costa de la Udeg. Correo: ‘paulina.mar79@gmail.com〉. Antonio Corgos López-Prado es profesor-investigador en el Departamento de Estudios para el Desarrollo Sustentable de Zonas Costeras en el Centro Universitario de la Costa Sur de la Universidad de Guadalajara. Correo: ‘acorgos@gmail.com〉. 
y Barra de Navidad-Melaque. Sin duda, las actividades económicas del sector turístico son relevantes para la región, pero en las comunidades rurales la agricultura, la ganadería y la pesca artesanal son de gran importancia, especialmente para los poblados marginados. Más aún, algunas de estas actividades son compatibles con la conservación. Las investigaciones sobre la diversidad biocultural demuestran que en México y en Jalisco las zonas mejor conservadas están habitadas por comunidades indígenas, de campesinos o productores primarios que mantienen prácticas tradicionales de pro- ducción agropecuaria y forestal. ${ }^{4}$ Incluso organismos gubernamentales han propuesto que la política pública tome en cuenta la asociación entre la biodiversidad y la diversidad cultural para recuperar los conocimientos y usos tradicionales de la biodiversidad. ${ }^{5}$

Nosotros abordamos el problema bajo los principios del modelo de conservación biocultural, ${ }^{6}$ pues en la costa de Jalisco y en el caso específico de «Careyitos» la diversidad biológica, la práctica de la pesca artesanal y los conocimientos de los pescadores con respecto al aprovechamiento sustentable de los ecosistemas ma-
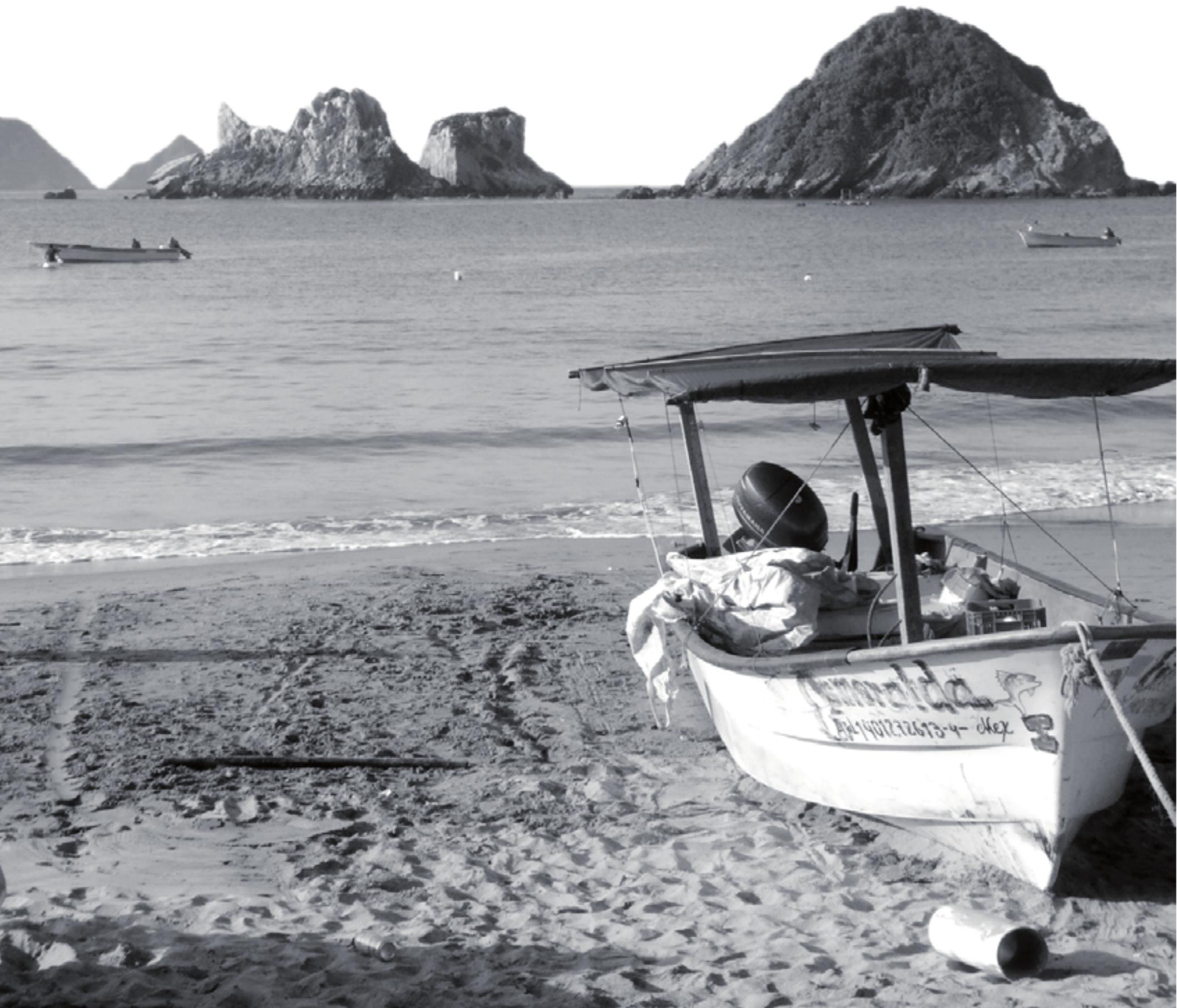
rinos están en riesgo de desaparecer. En cuanto a los factores que contribuyen a la destrucción de la megadiversidad, un informe elaborado por el Programa de las Naciones Unidas para el Medio Ambiente (PNUMA), la Secretaría de Medio Ambiente y Recursos Naturales (Semarnat) y el Instituto Nacional de Ecología (INE) apunta que los más agresivos son los contaminantes vertidos en los afluentes que desembocan en el océano, la extracción excesiva de recursos maderables y la captura de especies de forma indiscriminada. ${ }^{7}$ Además de estos factores, nuestras investigaciones revelan que una de las amenazas más serias a la conservación de biodiversidad en la costa de Jalisco es la «apropiación» del territorio por empresas inmobiliarias o particulares que pretenden desarrollar áreas turísticas o residenciales.

En ese sentido, es pertinente partir de los procesos económicos y políticos implicados en el problema. Para ello, recuperamos los planteamientos de David Harvey, quien argumenta que una de las características del capitalismo es su capacidad de crear y destruir geografías, lo cual supone cambios en el uso de los suelos con la finalidad de aumentar el valor monetario de la tierra mediante la inversión en infraestructura. A este tipo de procesos le denomina destrucción creativa del territorio. ${ }^{8}$ Relacionado con esto, Harvey hace alusión a una tendencia cada vez más visible a nivel global: la acumulación por desposesión, que consiste en la adquisición de territorio con el objetivo de insertarlo en el mercado como objeto de especulación financiera o de utilizarlo como un medio de absorción del capital excedente. La acumulación por desposesión por lo general conlleva el despojo de bienes comunes, privatización y expropiación; la modificación de relaciones sociales y la expulsión forzosa de las comunidades preexistentes. ${ }^{9}$

Una muestra de que estos procesos se están llevando a cabo en la costa de Jalisco es el hecho de que, en el municipio de La Huerta, 33 de las 36 playas se encuentran en manos de particulares a pesar de que ello representa una violación al artículo 27 la Constitución Política de México. ${ }^{10}$ En efecto, de acuerdo a la ley, las playas y otros sitios que concentran recursos naturales o culturales valiosos son «patrimonio de la nación», es decir, su «uso y disfrute» son derechos colectivos. Existe una manera de que particulares obtengan concesiones temporales, pero la misma ley establece que los productores primarios agrupados en cooperativas, ejidos o asambleas de comuneros tendrán preferencia para obtener las concesiones, situación que no ha ocu- rrido en los hechos. En los últimos años, en Jalisco se han otorgado permisos a empresas que especulan con el territorio y que pretenden o han construido complejos turísticos o habitacionales de lujo. En varios casos, la cesión de derechos ha provocado el desalojo de comunidades y cooperativas de pescadores, el uso de la fuerza pública, detenciones arbitrarias, encarcelamientos y amenazas a la integridad física de los opositores como en el caso de las playas de Tenacatita y Careyitos. Desde nuestro punto de vista, la figura legal de la «concesión» ha sido utilizada en favor de la acumulación por desposesión en detrimento de los derechos ciudadanos y de la conservación de la diversidad biocultural. Aunada a la mala gestión de las concesiones, la compra-venta de predios colindantes con zonas federales marítimo-terrestres ha generado privatizaciones de facto, pues se impide el paso alegando el derecho a la propiedad privada a pesar de que la ley obliga a los terratenientes a permitir e incluso facilitar el ingreso a las zonas federales.

\section{Pesca ARtesanal: Alternativa PARA LA CONSERVACIÓN}

La pesquería artesanal o ribereña es una práctica tradicional que llevan a cabo unidades familiares. La Organización de las Naciones Unidas para la Agricultura (FAO, por sus siglas en inglés) informa que los productos obtenidos de la pesquería artesanal se destinan principalmente al consumo local. ${ }^{11}$ En la literatura se han destacado sus ventajas socioeconómicas y ecológicas con respecto a la pesca industrial. ${ }^{12}$

En contraste, la pesquería industrial es gestionada por corporaciones que poseen embarcaciones con una gran capacidad productiva y los propietarios retienen la mayor parte de las utilidades generadas por la extracción y la comercialización de los recursos marinos. En cuanto al impacto ambiental, además de que bajo este modelo se sustraen masivamente especies con valor comercial, se ha documentado que sus métodos de captura diezman poblaciones de otras especies que no les reportan beneficios económicos.

En contrapartida, la pesca artesanal se compone por un gran número de embarcaciones pequeñas, también de propiedad privada, pero la distribución de la riqueza es más equitativa. Algunos investigadores afirman que emplea a un mayor número de personas de 
forma directa e indirecta y que sostiene económicamente a muchos más dependientes que la pesca industrial. ${ }^{13}$ En la costa de Jalisco trabajan hasta tres tripulantes en cada embarcación, pues se trata de una actividad que se realiza en colaboración. Otra de las ventajas es la contribución al desarrollo de mercados locales, al llevarse a cabo intercambios con transportistas, fabricantes de hielo, de aparejos, talleres de reparación de motores, pescaderías, restaurantes, hoteles. Respecto al impacto ambiental, las embarcaciones requieren un menor consumo de combustible y las capturas son mucho más selectivas, incluso se sustraen cantidades hasta 20 veces menores de especies acompañantes. Con todo, y en términos generales, los pescadores de ribera practican su arte de manera sustentable. Están conscientes de que el mar es el medio que sostiene la vida e identidad de sus comunidades; poseen conocimientos valiosos con relación a los ciclos vitales de las especies marinas, además de los factores que dañan los ecosistemas.

En Jalisco, la práctica de la pesca artesanal es común, pero presenta diversos problemas. La Comisión Nacional de Acuacultura y Pesca (Conapesca) reconoce, entre las carencias más importantes, la escasez en infraestructura y el rezago social de las comunidades de pescadores. ${ }^{14}$ Por nuestra parte, para conocer la importancia de la pesca, realizamos un diagnóstico que consistió en la aplicación de una encuesta a los representantes de las 44 cooperativas registradas en los municipios costeros de Jalisco que tienen litoral, durante el periodo del 2 de febrero al 15 de marzo de 2011. Los datos que obtuvimos arrojan que: $a$ ) la flota pesquera está compuesta por pequeñas embarcaciones denominadas pangas, que son de fibra de vidrio y tienen menos de 10 metros de eslora, con un promedio de 7.8 metros, con un motor «fueraborda» de entre 48 y $65 \mathrm{CV}$; b) en ellas trabajan de uno a cuatro tripulantes, quienes por lo regular salen a pescar de tres a cinco días por semana, dependiendo de las condiciones climatológicas y del estado del mar, la distancia a la zona de pesca y el arte empleado (tipo de pesca), y c) la infraestructura es insuficiente y precaria, se cuentan con pocas instalaciones adecuadas para el amarre de las embarcaciones, así como para el procesamiento y conservación de los productos pesqueros. De las 44 cooperativas, tan sólo dos disponen de embarcadero para atracar; en el resto de los casos varan las pangas en playas, esteros o canales; la mayoría no cuenta con los espacios y las herramientas necesarias como mesas de trabajo, básculas, bodegas, máquinas de hielo, congeladores, refrigeradores y vehículos. Con respecto a su importancia económica, Conapesca reporta que la producción en Jalisco en 2011 fue de 14,454 toneladas, con un valor de 195.25 millones de pesos. Así, no se trata de una actividad marginal, por el contrario, es una fuente importante de ingresos y alimentos.

Calculamos que 14,274 personas viven directamente de la pesca en los municipios jaliscienses con litoral. ${ }^{15}$ Tan sólo en el municipio de La Huerta — donde se ubica Careyitos- el 18.5\% de la población económicamente activa se dedica a pescar. En definitiva, una cantidad importante de familias encuentra su sustento en esta práctica que permite una distribución más equitativa del ingreso, que puede fortalecer los mercados locales y que es compatible con una visión de conservación que contempla la participación de las comunidades. Sin embargo, corre el riesgo de desaparecer debido a la privatización de las playas y sitios de desembarco.

\section{Pescadores artesanales frente}

\section{AL DESPOJO: EL CASO DE CAREYITOS}

La playa conocida como Careyitos se encuentra en la posición $19^{\circ} 26^{\prime} \mathrm{N}, 105^{\circ} 01^{\prime} \mathrm{w}$ y tiene una longitud de 485 metros. Pertenece al municipio de La Huerta, Jalisco, y forma parte de la zona conocida como Costa Alegre. Al oriente colinda con un cuerpo de agua dulce, conocido como laguna Careyitos y enseguida con la playa Teopa, que es un sitio de protección de tortugas marinas. A una distancia de aproximadamente tres kilómetros tierra adentro se localiza el polígono que demarca la Reserva de la Biósfera Chamela-Cuixmala.

En Careyitos se practica la pesca artesanal desde hace más de 50 años. El centro de población donde residen, la localidad de Emiliano Zapata, se encuentra a tres kilómetros de la playa. Careyitos es donde se llevan a cabo actividades de convivencia familiar y comunitaria. Además, los pescadores utilizan la playa para varar sus embarcaciones, descargar las capturas y gestionar de manera colectiva un restaurante en donde ofrecen alimentos a los visitantes. Eligieron el lugar porque es apto para varar sus embarcaciones, porque tiene acceso por tierra y porque es cercano a la comunidad; incluso los propios pescadores construyeron un camino de 200 metros de longitud que permite bajar desde la carretera hasta la playa. ${ }^{16}$ 


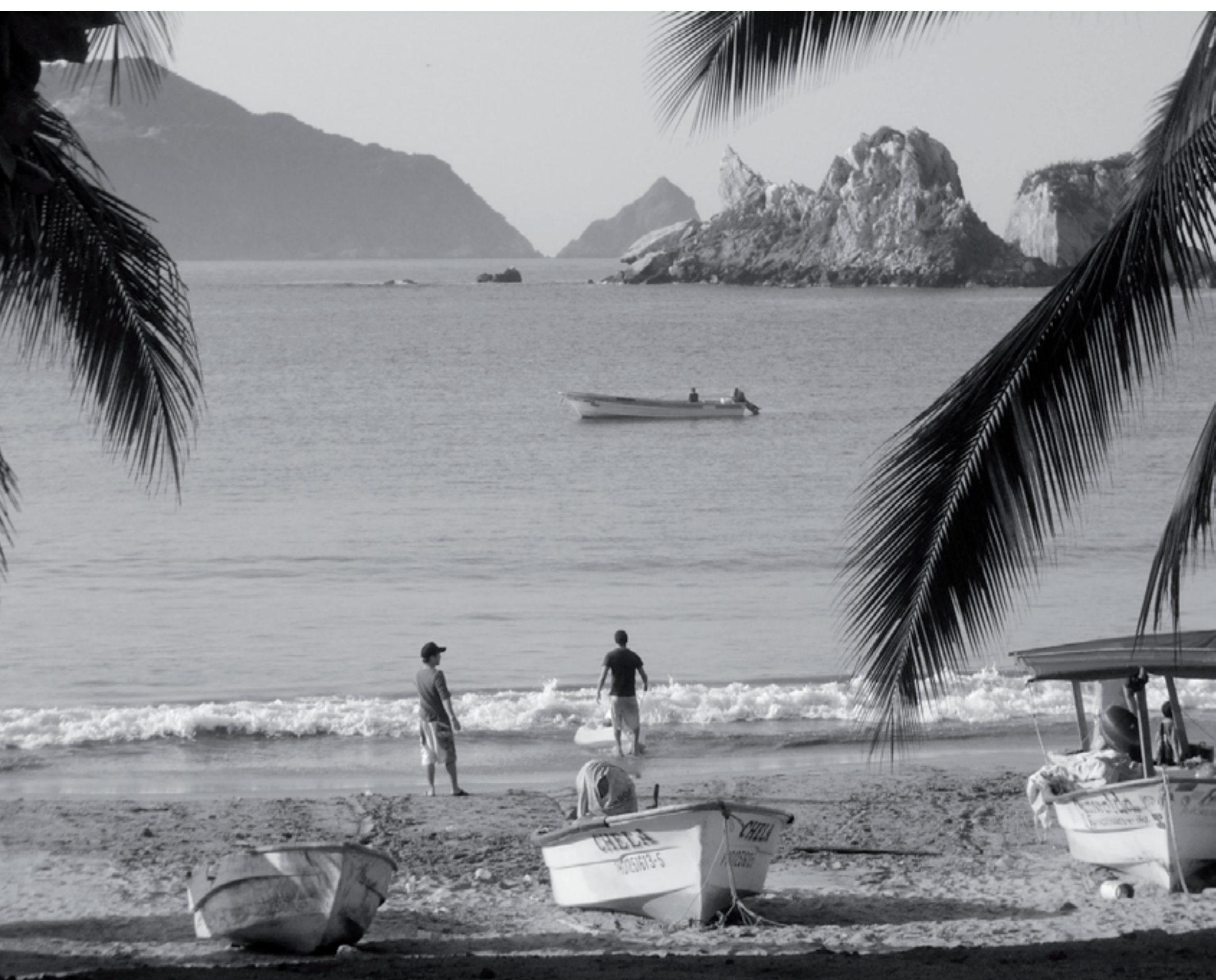


De acuerdo a las normas mexicanas que obligan a los pescadores a asociarse en cooperativas, los pescadores de Careyitos formaron la Sociedad Cooperativa de Pesca de Ribera Punta Pérula. En términos económicos, su labor es la principal fuente de ingresos de aproximadamente 200 personas. Los miembros de la cooperativa solamente se dedican a la pesca, pues no poseen tierras para sembrar. Obtuvieron una concesión para el uso de la playa Careyitos en los años ochenta.

El conflicto socioambiental que gira en torno al uso de la zona federal marítimo-terrestre que ocupan los pescadores empezó en 1991, cuando la empresa Imágenes y Espectáculos de Lujo, S.A. de C.V. (IEL en adelante) adquirió las tierras colindantes a Careyitos. El terreno era propiedad de un particular quien permitía el libre acceso a la playa, de acuerdo a la ley. Para la cooperativa, el cambio de propietarios trastocó la vida cotidiana y les impuso la necesidad de tomar acciones frente a la amenaza de ser expulsados definitivamente. El primer intento de la empresa para desalojarlos se dio en 2001, cuando empleados de IEL colocaron una barrera para impedir la entrada por el camino que abrieron los propios pescadores. En aquella ocasión, el gobierno municipal de La Huerta intervino en favor de la cooperativa. Representantes de la empresa, del municipio y de la Junta Directiva de la cooperativa firmaron un convenio en el que IEL se comprometió a permitir el acceso y retiró la barrera.

En 2005, IEL solicitó la concesión de uso de la playa y buscó la anuencia de la Secretaría de Medio Ambiente y Recursos Naturales (Semarnat) para construir un hotel, residencias de lujo y una marina en la laguna. La Semarnat otorgó el permiso. No obstante, al revisar el informe sobre el impacto ambiental que presentó IEL, investigadores de la Universidad de Guadalajara y de la Universidad Nacional Autónoma de México emitieron dictámenes técnicos que alertaron sobre los daños que sufrirían la Reserva Chamela-Cuixmala y Teopa, entre otros impactos graves que IEL intentó minimizar. Con ello, la Semarnat se vio obligada a revocar el permiso.

En el mismo año, la cooperativa tramitó la renovación de la concesión que estaba a punto de concluir y obtuvieron la ratificación. Siete meses más tarde, se les notificó que se cancelaba en razón de que IEL había solicitado utilizar el mismo sitio. La cooperativa recurrió al amparo legal como defensa y los pescadores decidieron seguir trabajando en Careyitos. Un año más tarde se les informó que el amparo no fue sometido a estu- dio por haberse recibido de forma «extemporánea». Se ampararon nuevamente, pero hasta la fecha no se ha resuelto el caso. Los pescadores están convencidos de que las autoridades federales respaldan las tentativas de expulsarlos, ${ }^{17}$ pero aún así, continúan luchando por la vía legal y ocupando la playa.

En 2009, IEL obtuvo una concesión de 13,873 m² en Careyitos, con una vigencia de 15 años. El problema es que ésta se traslapa en $20 \mathrm{~m}^{2}$ con el terreno que utilizan los pescadores, que comprende un área de 4,160 $\mathrm{m}^{2}$. Dos años más tarde, a pesar de que la Semarnat canceló el permiso de uso de suelo a los pescadores, la Secretaría de Agricultura, Ganadería, Desarrollo Rural, Pesca y Alimentación (Sagarpa) entregó a la cooperativa un subsidio por 5 millones de pesos para la construcción de una «lonja pesquera», es decir, un local que cuenta con las condiciones necesarias para procesar las capturas. Cuando comenzó la construcción del local, IEL interpuso una demanda por invasión de propiedad privada, argumentando que los pescadores invaden los 20 metros del terreno que les fue concedido, mismos que corresponden al camino de acceso a la playa. La Semarnat clausuró la obra y la cooperativa se vio obligada a regresar los recursos económicos.

El conflicto se intensificó a raíz de que en julio de 2011 fue asesinado el entonces presidente de la cooperativa, Aureliano Sánchez. El crimen no se ha aclarado, pero para los pescadores su muerte significa una «advertencia» de las medidas que están dispuestos a tomar los empresarios para defender su inversión y consideran que ellos se encuentran en riesgo de ser objeto de violencia. ${ }^{18}$ Un año más tarde, en julio de 2012, IEL decidió colocar una puerta y contratar los servicios de una corporación de seguridad privada - quienes portan armas de fuego- para controlar el acceso a la playa. La reacción de los miembros de la cooperativa no se hizo esperar; solicitaron el apoyo de las autoridades municipales y lograron que el caso se difundiera en algunos medios de comunicación de Jalisco. A través de la intervención del municipio, la empresa permite el acceso, pero no retiró la puerta, ni la vigilancia de los guardias, de manera que solamente se puede ingresar caminando hacia la playa. Frente a los reclamos de los pescadores y medios de comunicación la respuesta de los delegados de la Semarnat y de la Procuraduría Federal de Protección al Ambiente (Profepa) fue contundente: en su opinión no hay violación de derechos porque el cierre del camino no es total sino parcial. ${ }^{19}$ 
Con ello, crecen las sospechas de la alianza entre la empresa y los agentes gubernamentales.

La imposibilidad de que los pescadores ingresen sus vehículos a la playa ha generado pérdidas económicas y un esfuerzo extraordinario en el trabajo, pues ahora deben transportar los productos en carretillas a través de una pendiente de 200 metros. De acuerdo a sus testimonios, las capturas han disminuido, con lo que se ha perjudicado la economía familiar y el mercado local en el que participan. En suma, a partir de 2011 el conflicto se agudizó y colocó a la cooperativa en una situación de desventaja muy marcada frente a su adversario: perdieron la oportunidad de contar con infraestructura adecuada y se obstaculizó la realización de sus labores. Además, están en riesgo de ser aprehendidos por las autoridades a causa de la demanda de «invasión de propiedad privada» que interpuso la empresa.

Por su parte, IEL demostró su capacidad de obtener el respaldo de autoridades para dificultar el trabajo de los pescadores y de desatar un clima de amenazas. Es importante mencionar que en las entrevistas los pescadores comentaron que no se oponen a que la empresa lleve a cabo sus proyectos siempre y cuando respeten las normas ambientales y su derecho a hacer uso de la playa con las condiciones que requieren. Incluso han buscado nuevamente el diálogo con la mediación de las autoridades municipales, pero la empresa se ha negado, situación que demuestra el endurecimiento de su posición frente al conflicto. Su rechazo invita a pensar que desde su punto de vista los pescadores no son sujetos dignos de interlocución. Tampoco se ha pronunciado en torno a la indemnización o compensación por los daños que han causado. Los cooperativistas persisten en su lucha, en un ambiente de hostilidad y violencia simbólica. La falta de aplicación del Estado de derecho por parte de las instituciones implicadas no han disminuido su voluntad; se mantienen como un sujeto colectivo capaz de impedir - hasta el momento- la destrucción creativa del paisaje y el desarrollo exitoso de la acumulación por desposesión, que para ellos significaría la pérdida del sustento, la identidad y la comunidad.

\section{Referencias}

1 Secretaría de Medio Ambiente y Desarrollo Territorial (Semadet) (s/f), «Ordenamiento Ecológico de la Región Costa de Jalisco», 〈http://siga.jalisco.gob.mx/moet/〉.

2 Semadet (s/f), op. cit.

3 Miguel de la Madrid, (1986), «Decreto por el que se determinan como zonas de reserva y sitios de refugio para la protección, conservación, repoblación, desarrollo y control de las diversas especies de tortuga marina, los lugares en que anida y desova dicha especie», 〈www.conanp.gob.mx/sig/decretos/ santuarios/Pla yastortuga.pdf $\rangle$.

4 Darcy Tetreault y Lucio, Carlos (2011), «Jalisco. Pueblos indígenas y regiones de alto valor biológico», Revista Espiral. Estudios sobre Estado y Sociedad, volumen XVIII, número 51, pp. 165-199.

5 Comisión Nacional para el Conocimiento y Uso de la Biodiversidad (Conabio) y Secretaría de Medio Ambiente y Recursos Naturales (Semarnat) (2009), Cuarto informe nacional de México sobre diversidad biológica, 〈http://www. conabio.gob.mx/institucion/cooperacion_internacional/ doctos/4oInforme_CONABIO.pdf>

6 Víctor Toledo (2010), «La conservación de la biodiversidad», en Víctor Toledo (coordinador), La biodiversidad de México. Inventarios, manejos, usos, informática, conservación e importancia cultural, México, Fondo de Cultura Económica, Conaculta.

7 Programa de las Naciones Unidas para el Medio Ambiente (PNUMA), Secretaría de Medio Ambiente y Recursos Naturales (Semarnat) e Instituto Nacional de Ecología (INE) (2004), «Perspectivas del medio ambiente en México. Informe GEO 2004», México.

8 David Harvey (2000), Espacios de esperanza, Madrid, Akal.

9 David Harvey (2012), El enigma del capital y la crisis del capitalismo, Madrid, Akal.

10 El Informador (2012), «En La Huerta, 33 de 36 playas están privatizadas», El Informador, 23 de julio.

11 Food and Agriculture Organization (FAO) (2012), Fisheries and Aquaculture topics. Fish capture technology. Topics Fact Sheets, 〈http://www.fao.org/fishery/topic/3384/en〉.

12 Jennifer Jacquet y Daniel Pauly (2008), «Funding Priorities: Big Barriers to Small-scale Fisheries», Conservation Biology, volumen 22, número 4, pp. 832-835. Daniel Pauly (2006), «Major trends in small-scale marine fisheries, with emphasis on developing countries, and some implications for the social sciences», Maritime Studies, volumen 4, número 2, pp. 7-22.

13 Jacquet y Pauly (2008), op. cit.; Pauly (2006), op. cit.

14 Comisión Nacional de Acuacultura y Pesca (Conapesca) (2011), 
«Anuario Estadístico de Acuacultura y Pesca», 〈http://www. conapesca.sagarpa.gob.mx/wb/cona/cona_anuario_estadistico_de_pesca>.

15 Cálculo propio basado en datos obtenidos de Sagarpa (2011), Cierres anuales de producción pesquera, 〈http://www.siap. gob.mx/index.php?option=com_wrapper\&view=wrapper\&I temid $=351$.

16 Entrevista a Carlos López (seudónimo), miembro de la Cooperativa Punta Pérula, en La Huerta, Jalisco, en agosto de 2012.
17 Entrevistas a Adolfo Sánchez y Carlos López (seudónimos), miembros de la cooperativa, en La Huerta, Jalisco, en agosto de 2012.

18 Entrevista a Rafael Conteras, Carlos López y Adolfo Sánchez (seudónimos), en La Huerta, Jalisco, en julio y agosto de 2013.

19 La Jornada Jalisco (2012), «Sí hay cierre en playa Careyitos, pero es parcial: Profepa», 13 de julio, http://www.lajornadajalisco.com.mx/2012/07/13/si-hay-cierre-en-playa-careyitos-pero-es-parcial-profepa/>.

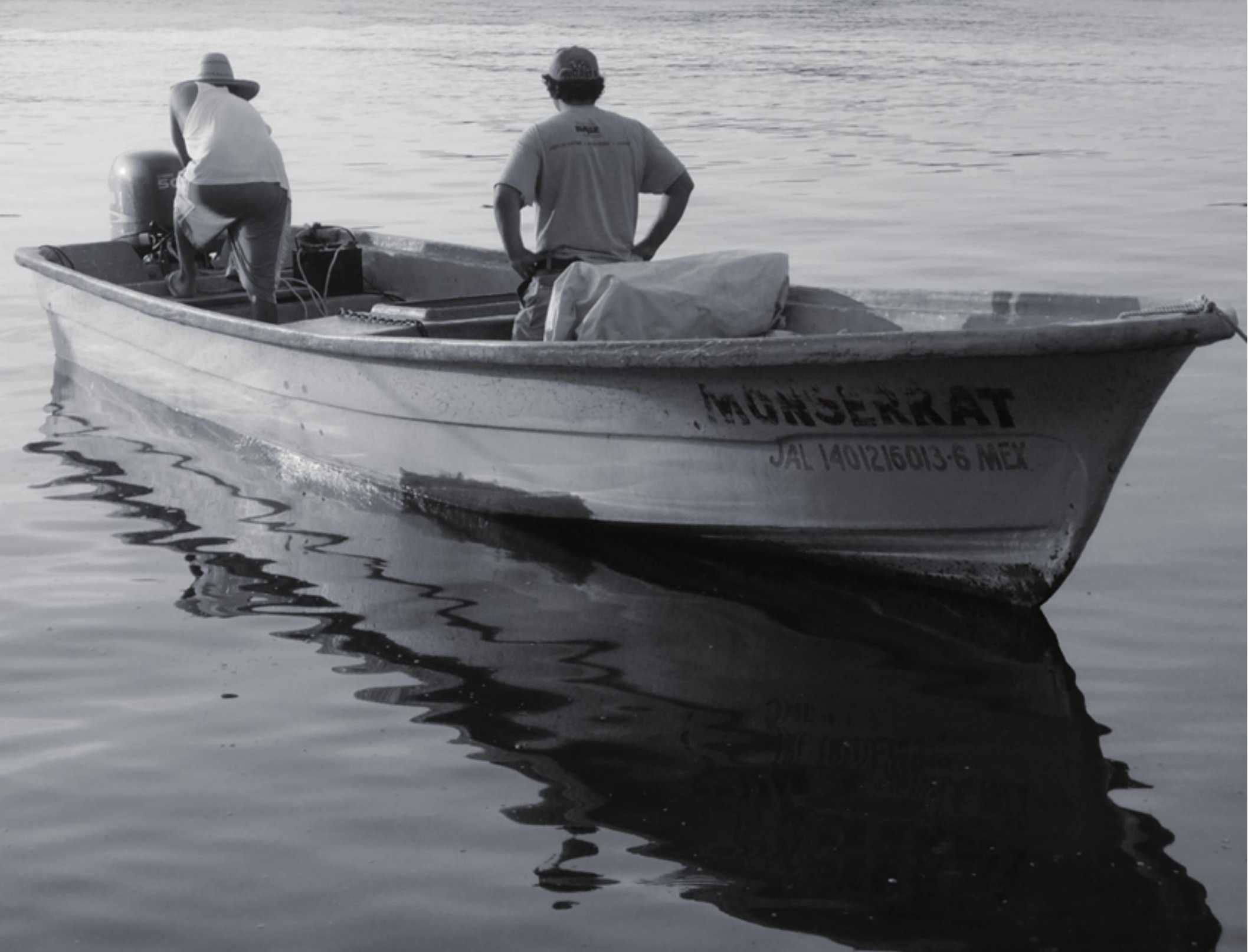

